Published in final edited form as:

Nutr Clin Pract. 2011 August ; 26(4): 463-473. doi:10.1177/0884533611413778.

\title{
The Effects of an Oral Supplement Enriched With Fish Oil, Prebiotics, and Antioxidants on Nutrition Status in Crohn's Disease Patients
}

\author{
Dawn M. Wiese, MD¹, Bret A. Lashner, MD, MPH², Edith Lerner, PhD³, Stephen J. \\ DeMichele, $\mathrm{PhD}^{4}$, and Douglas L. Seidner, $\mathrm{MD}^{5}$ \\ ${ }^{1}$ Internal Medicine, Vanderbilt University Medical Center, Nashville, Tennessee \\ ${ }^{2}$ Digestive Disease Institute, Cleveland Clinic, Cleveland, Ohio \\ ${ }^{3}$ Department of Nutrition, Case Western Reserve University, Cleveland, Ohio \\ ${ }^{4}$ Abbott Nutrition, Abbott Laboratories, Columbus, Ohio \\ ${ }^{5}$ Division of Gastroenterology, Hepatology and Nutrition, Vanderbilt University Medical Center, \\ Nashville, Tennessee
}

\begin{abstract}
Background-Research in the treatment of Crohn's disease (CD) supports anti-inflammatory benefits of n-3 fatty acids from fish oil, prebiotics, and antioxidants. A nutritionally balanced inflammatory bowel disease nutrition formula (IBDNF) enriched with these compounds has the potential to improve nutrition status and disease activity in $\mathrm{CD}$.
\end{abstract}

Methods-This is an open-label pilot study investigating the effects of IBDNF on nutrition status in $\mathrm{CD}$ patients. Twenty-eight patients with active $\mathrm{CD}$ on stable medication were asked to consume $16 \mathrm{oz}$ of IBDNF/d for 4 months. Nutrition status was assessed with dual-energy X-ray absorptiometry scans and serum micronutrient levels. Disease activity and quality of life were measured using the Crohn's Disease Activity Index (CDAI) and the Inflammatory Bowel Disease Questionnaire (IBDQ).

Results-Twenty patients completed the final visit. After 4 months, there was a significant decrease in plasma phospholipid levels of arachidonic acid with increases in eicosapentaenoic acid (EPA) and docosahexaenoic acid. Ten patients had a final EPA concentration of $>2 \%$. There was improvement in fat-free and fat mass in patients with final EPA $>2 \%(P=.014$ and $P=.05)$. Vitamin D (25-OH) levels improved in all patients $(18.5-25.9 \mathrm{ng} / \mathrm{mL}, P<.001)$. Those with EPA $>2 \%$ had significantly lower CDAI (116 \pm 94.5 vs $261.8 \pm 86.5 ; P=.005)$ and higher IBDQ $(179.1 \pm 26.6$ vs $114.6 \pm 35.9, P<.001)$ compared to those with EPA $<2 \%$.

Conclusions-IBDNF has the potential to deposit fat-free and fat mass, improve vitamin D status, and improve quality of life in CD patients.

(C) 2011 American Society for Parenteral and Enteral Nutrition Permissions: http://www.sagepub.com/journalsPermissions.nav

Address correspondence to: Dawn Wiese, MD, Vanderbilt University Medical Center, B-510 TVC, Box 396, Nashville, TN 37232-5283; dawn.m.wiese@ vanderbilt.edu. 


\section{Keywords}

enteral nutrition; gastroenterology; fatty acids; Crohn's disease; prebiotics; fish oils

\section{Background}

Crohn's disease (CD) is an idiopathic inflammatory bowel disease (IBD) that can affect any part of the gastrointestinal tract. $\mathrm{CD}$ is often associated with nutrition deficiencies due to impaired absorption, nutrient loss, inadequate food intake, and drug-nutrient interactions. Patients are typically deficient in both macro- and micronutrients throughout the course of their disease, as reflected by low plasma levels of albumin, vitamin $\mathrm{B}_{12}$, folate, $25-\mathrm{OH}$ vitamin $\mathrm{D}$, iron, and zinc. ${ }^{1}$ Recognition and correction of malnutrition are an important part of both primary and supportive therapy for CD patients. Medications used to treat $\mathrm{CD}$ often reduce disease activity but do not always restore nutrition status. ${ }^{2,3}$

Nutrition intervention is an important part of the clinical management of patients with IBD. Parenteral nutrition (PN), enteral nutrition (EN), and exclusion diets have all been used to restore nutrient deficiencies and diminish inflammation. Previous studies have shown that $\mathrm{EN}$ as the sole source of nutrition is less likely than corticosteroids to induce remission in CD. ${ }^{4-6}$ Despite its inferiority to corticosteroids, EN has been shown to decrease ileal inflammation in patients with active $\mathrm{CD}$ and therefore has the potential to be used as an adjuvant to other treatment. ${ }^{7}$ Providing CD patients with a nutritionally complete supplement enriched with anti-inflammatory ingredients is a logical approach to improve disease control and nutrition status.

Fish oil contains long-chain $\omega-3$ polyunsaturated fatty acids (PUFAs), which decrease inflammation by altering the expression of inflammatory genes and interfering with the production of arachidonic acid (AA) metabolites such as leukotriene $\mathrm{B}_{4}$ and thromboxane $\mathrm{A}_{2} \cdot{ }^{8,9}$ The anti-inflammatory actions of fish oil have led to its investigation as a therapeutic agent for many chronic inflammatory diseases, including IBD. ${ }^{10,11}$ Although animal models and epidemiologic studies support the use of fish oil in $\mathrm{CD}$, clinical studies have provided mixed results regarding its efficacy. ${ }^{12-16}$

Indigestible fiber, which is a type of prebiotic, promotes the growth of beneficial bacterial such as bifidobacteria and lactobacillus in the large intestine. ${ }^{17,18}$ The indigestible fiber is fermented by the endogenous flora in the colon into short-chain fatty acids (SCFAs) and gases. SCFAs have been shown to be the primary fuel for the mucosa of the large bowel and can provide energy to cells starved as a result of chronic inflammatory activity and can block inflammatory mediators associated with IBD. ${ }^{19,20}$ Clinical studies have shown that enemas containing butyrate, the predominant SCFA in the colon, reduce disease activity and symptoms in ulcerative colitis patients..$^{20,21}$

Increased reactive oxygen species (ROS) appear to play a role in intestinal inflammation in IBD. ${ }^{22}$ Antioxidants are naturally occurring compounds that can combat the effects of ROS. Serum and mucosa antioxidant levels are typically low in IBD patients, whereas ROS are high when compared with healthy controls. ${ }^{23,24}$ In addition, increased levels of ROS and 
decreased levels of antioxidants correlate with disease activity. Clinical studies of antioxidants in $\mathrm{CD}$ are limited.

A nutritionally complete high-protein liquid formula containing fish oil, prebiotics, and antioxidants was developed to reverse inflammation and provide supplemental nutrition to patients with IBD. This inflammatory bowel disease nutrition formula (IBDNF) has been examined in a randomized controlled trial in a group of 120 ulcerative colitis patients with mild to moderate disease. ${ }^{25}$ Patients consumed an amount of IBDNF equal to one-third of their daily energy expenditure or an equal volume of a carbohydrate-based placebo for 6 months. At the conclusion of the study, the IBDNF group had a 35\%-65\% greater decrease in corticosteroid dosage compared with the controls with similar reductions in disease activity, thus supporting its use as an adjuvant therapy in patients with ulcerative colitis. We hypothesized that CD patients would have improvements in specific nutrition deficits as well as disease activity and quality of life by consuming IBDNF over a 4-month period.

\section{Materials and Methods}

\section{Patients}

Patients being seen at the Cleveland Clinic IBD Center were screened via electronic medical record. Eligible patients were 18 years or older, had been diagnosed with $\mathrm{CD}$ for at least 6 months, had clinical signs of active disease as determined by their primary gastroenterologist, and were on stable medication dosing for at least 1 month. Patients with severe disease requiring hospitalization or surgery, a history of bleeding disorders, a need for anticoagulation therapy, or currently receiving biologic therapy were excluded from the study. Patients with fistulizing CD as their principal disease manifestation, severe malabsorption, or short bowel syndrome were also excluded because it was believed that the supplement would be ineffective in these conditions. We obtained Cleveland Clinic Institutional Review Board approval for the study.

\section{Supplement}

IBDNF (Abbott Nutrition, Abbott Laboratories, Columbus, OH) consists of a novel oil blend containing fish oil (1.09 $\mathrm{g}$ eicosapentaenoic acid [EPA] and $0.46 \mathrm{~g}$ docosahexaenoic acid [DHA] per $8 \mathrm{oz}$ ), a fermentable prebiotic/fiber system (fructooligosaccharide and gum arabic), and increased levels of antioxidant vitamins and minerals as a nutritionally complete ready-to-feed drink (Table 1). The vanilla-flavored supplement has a caloric density of 1.3 $\mathrm{kcal} / \mathrm{mL}$ with a high protein content. Patients were instructed to drink two 8-oz cans each day for 4 months, which is approximately $614 \mathrm{kcal} / \mathrm{d}$. The study length was based on the time that it would take the fish oil to reach an adequate concentration to allow sufficient changes in disease activity while minimizing supplement fatigue.

\section{Compliance}

Patients were instructed to stop all nutrition supplements 2 weeks prior to their initial lab work and initiation of the oral supplement. All other medications were kept constant throughout the 4-month trial with the exception of corticosteroids, which could be tapered at the discretion of the treating physician. Patients were not permitted to take nonsteroidal anti- 
inflammatory drugs because of the potential similar anti-inflammatory activity as the supplemented $\omega$-3 PUFAs. Antibiotics were avoided during the 4-month period to prevent significant changes in the intestinal flora. Patients who developed a nonintestinal infection were allowed up to 10 days of antibiotic administration. A diary was provided to all patients to record daily can intake, bowel function, abdominal pain, sense of general well-being, and medication use. Every 4 weeks, the diaries were collected by mail, and patients were contacted to encourage compliance with the oral supplement. Plasma phospholipid fatty acid profiles were measured and can be interpreted as a biomarker of compliance. Plasma phospholipids were isolated from the total lipids in plasma by thin-layer chromatography and quantitated by gas chromatography as previously described. ${ }^{26}$ Normal human plasma phospholipid levels of EPA without fish oil supplementation is $<1.0 \%$ of total plasma phospholipids. An elevation in EPA values can be used as an indication of oral supplement absorption.

\section{Measurements}

All measurements and questionnaires occurred at the time of enrollment ( 0 weeks) and at the time of completion (4 months). Patients who chose not to complete the 4-month trial had their exit measurements taken at time of study cessation.

Diet-No dietary restrictions were placed on patients other than to include two 8-oz cans of the supplement per day. To analyze changes in nutrient consumption before and after supplement intervention, dietary intake was assessed with a monthly 3-day food diary. Patients were asked to record their intake 2 weekdays and 1 weekend day each month.

Dietary Analysis-Food diaries from before and after supplement were entered into the Nutritionist Pro Version 4.10 (Axxya Systems, LLC, Stafford, TX). Foods were selected from the Food and Nutrient Database for Dietary Studies and the US Department of Agriculture (USDA) Standard Reference Database. Using the software, the 3 days were averaged to create a daily value for each nutrient intake. This daily intake was extracted for statistical analysis. The following nutrients were compared before and after supplement initiation: total kilocalories, protein (g), fat (g), carbohydrates (g), PUFAs (g), calcium (mg), folate, vitamin $\mathrm{D}$ (IU), vitamin $\mathrm{B}_{12}$, iron, total fiber, $\alpha$-linolenic acid, selenium, $\beta$-carotene, zinc, vitamin $\mathrm{E}$, and vitamin $\mathrm{C}$.

Body Composition-Body composition was assessed by whole-body dualenergy X-ray absorptiometry (DXA) scans. All scans were done with the same protocol and machine (Lunar Prodigy Pro; GE Medical Systems, Berkshire, UK) by experienced technicians. Data were extracted from DXA reports for total body fat mass (g), total body fat-free mass (g), body fat percentage, and total body estimated $\mathrm{T}$ score.

Markers of Micronutrient Deficiencies-Serum methylmalonic acid (MMA) and homocysteine (hcy) were measured using gas chromatography mass spectrometry and chemiluminescence immunoassay, respectively, to assess the adequacy of vitamin $\mathrm{B}_{12}$ and folate. Serum measurements were also conducted for 25-OH Vitamin D and parathyroid 
hormone (PTH) levels, both of which were measured by chemiluminescence immunoassay. All testing was performed by the Cleveland Clinic Reference Laboratory.

Disease Activity-Disease activity was assessed by the Crohn's Disease Activity Index (CDAI) and C-reactive protein (CRP) and quality of life by the Inflammatory Bowel Disease Questionnaire (IBDQ). The CDAI is a method to assess disease activity based on the number of liquid stools per week, abdominal pain, general well-being, extra-intestinal symptoms, use of antidiarrhea agents, abdominal masses, hematocrit, and body weight. ${ }^{27} \mathrm{~A}$ patient with a score of $>150$ is considered to have active disease. CRP is an acute-phase protein that is elevated in conditions of inflammation. In some studies, elevation of CRP correlates with active $\mathrm{CD} .{ }^{28-30} \mathrm{CRP}$ was measured using turbidimetric immunoassay in the Cleveland Clinic Reference Laboratory. A level $>1.0 \mathrm{mg} / \mathrm{dL}$ was considered elevated. The IBDQ consists of 32 multiple-choice questions that assess quality of life in inflammatory bowel disease. ${ }^{31}$ Scores $<170$ are considered poor quality of life.

\section{Statistical Methods}

This is an open-label pilot study investigating the nutrition effects of IBDNF on CD patients. The study's original goal was to recruit at least 26 patients to provide a power of $80 \%$ based on changes in the Prognostic Inflammatory and Nutritional Index (PINI) previously reported with infliximab. ${ }^{32}$ Analysis based on final levels of EPA was a post hoc analysis done because of lower than expected compliance rates and to emphasize changes in nutrition status rather than disease activity.

Descriptive statistics were computed for all variables. Results are expressed as mean $\pm \mathrm{SD}$ or median (25th, 75th percentiles) for continuous factors and frequency for gender, smoking status, disease location, and medication usage. Plasma phospholipid EPA levels below $2.0 \%$ represent $<1 \mathrm{~g}$ of EPA consumed ( $<8 \mathrm{oz}$ of IBDNF consumed per day) as previously observed with chronic feeding studies. ${ }^{25}$ Patients were separated into those with a final EPA level $>2.0 \%$ and $<2.0 \%$ as a marker of supplement intake and absorption. Comparisons between groups were done using Fisher's exact test for categorical data and $t$ tests or nonparametric Wilcoxon rank sum tests for continuous variables. Differences in nutrition status indicators between baseline and follow-up visits among compliers and noncompliers were estimated and Wilcoxon signed rank tests were used to assess statistical significance. $P$ $<.05$ was considered statistically significant. SAS version 9.2 software (SAS Institute, Cary, $\mathrm{NC}$ ) was used for all analyses.

\section{Results}

A total of 28 patients participated in the study. Enrolled patients were predominantly women (78.6\%), white (100\%), and nonsmokers (75\%) with an age range of 20-75 years. More than $50 \%$ of the patients had some colonic involvement of their CD, as evidenced by computed tomography (CT) enterography or colonoscopy. Twenty patients completed the follow-up measurements regardless of compliance. Of the 8 patients who left the study, 3 sought other medical therapy ( 2 pursued anti-tumor necrosis factor [TNF] medication and 1 enrolled in another clinical trial; all 3 left within 1 month of enrollment), 1 required surgery, 1 was intolerant to IBDNF and left the trial after 1 week, and 3 were unable to be contacted for 
follow-up. The baseline characteristics of patients were similar between those who completed the 4-month follow-up and the 8 patients who did not.

At baseline, all patients had plasma phospholipid EPA levels $<2 \%$ as would be expected with consumption of a normal Western diet. At completion, 10 patients had an EPA $>2 \%$ of total phospholipids, 5 were between $1 \%$ and $2 \%$, and 5 were $<1 \%$. Total can consumption over 4 months and can consumption per week were significantly associated with EPA $>2 \%$ but not with EPA $>1 \%(P=.04$ and $P=.07)$. The 10 patients with EPA levels double the normal values had a median intake of 11.8 cans per week, or $85 \%$ of the expected intake, compared with a reported 7.5 cans per week (54\%) among the other patients. We used this breakdown as a surrogate for compliance throughout the results and discussion. Complaints among the patients that may have been attributed to the supplement were nausea (6), excessive gas (3), incontinence or leakage of stool (3), hot flashes (2), and abdominal pain (1).

The 20 patients who completed the study had baseline characteristics that are illustrated in Table 2. There were no significant differences between the groups. The distribution of disease was as $45 \%$ ileocolonic, $35 \%$ ileal, and $20 \%$ colonic. Most patients were taking a corticosteroid (prednisone or budesonide), an aminosalicylate derivative, or an immunomodulator (methotrexate, 6-mecaptopurine, or azathioprine) at the time of enrollment. All patients remained on the same medication and dosing with the exception of corticosteroid dosing. There were only minor changes in corticosteroid dosage, with 1 patient in the EPA $>2 \%$ group stopping low-dose budesonide $(3 \mathrm{mg}$ ) and 2 patients in the EPA $<2 \%$ group increasing prednisone by $5 \mathrm{mg}$. Body mass index (BMI) was well within the normal range, with a median of $22.6 \mathrm{~kg} / \mathrm{m}^{2}(20.3,25.0)$. Fourteen patients fell within a normal weight range with a BMI of $18.5-25 \mathrm{~kg} / \mathrm{m}^{2}, 5$ were overweight with a BMI $>25-30$ $\mathrm{kg} / \mathrm{m}^{2}$, and only 1 patient was underweight with a BMI $<18.5 \mathrm{~kg} / \mathrm{m}^{2}$. Patients were deficient in $25-\mathrm{OH}$ vitamin $\mathrm{D}$ (mean $18.5 \pm 8.3 \mathrm{ng} / \mathrm{mL}$ ) and had a normal range for PTH, methylmalonic acid, and homocysteine concentrations. There were no significant differences between the final groups in these variables. Overall, patients had active disease based on CDAI and IBDQ at baseline but normal CRP. There was a nonsignificant but clinically relevant difference in CDAI between the subgroups (168 vs 255 , respectively). This can be partially attributed to the small sample size and large variation in test results.

\section{Fatty Acid Composition}

Baseline plasma phospholipid fatty acid composition was similar among all groups and was consistent with a recent study in CD patients. ${ }^{33}$ The final plasma phospholipid fatty acid levels were significantly different among the groups (Table 3, Figure 1). Plasma fatty acid composition showed improvement overall with increasing $\omega-3$ PUFA and decreasing $\omega-6$ PUFA. As expected, among those with higher EPA levels, there was a significant increase in DHA and a decrease in AA (Figure 1).

\section{Nutrient Intake}

There were no differences in baseline nutrient intake in patients who completed the study. Table 4 outlines nutrient intake before and after supplement. Incorporating reported 
supplement intake, there was an increase in energy intake among all patients who consumed IBDNF $(+145 \pm 144.69 \mathrm{kcal}, P=.30)$. Carbohydrates, specifically soluble fiber, and many of the micronutrients increased in all patients' diets after the addition of the supplement. $\omega-3$ PUFA increased significantly $(+2.7 \pm 0.29 \mathrm{~g}, P<.001)$ despite no overall change in total amount of fat consumed $(-4.3 \pm 7.0 \mathrm{~g}, P=.55)$. Among the group with EPA $>2 \%$, the only notable change in their nonsupplement dietary intake was a small decrease in total energy $(-257.3 \pm 116.6 \mathrm{kcal}, P=.02)$ and carbohydrates $(-41.5 \pm 12.6 \mathrm{~g}, P=.014)$. The sum of the diet and oral supplement resulted in a statistically significant increase in total energy, carbohydrates, calcium, vitamin D, vitamin $\mathrm{B}_{12}$, soluble fiber, folate, DHA and EPA, and antioxidants zinc, vitamin C, and vitamin E (Table 4). Based on current Dietary Reference Intake (DRI), baseline deficiencies of folate and calcium corrected after IBDNF and approached the DRI for total fiber and vitamin D.

\section{Nutrition Outcomes}

BMI, DXA fat mass, and DXA fat-free mass increased significantly in those with EPA $>2 \%$ after 4 months (Table 3). There was also an increase in $25-\mathrm{OH}$ vitamin $\mathrm{D}$ in both groups $(+9.5, P=.002$ and $+4.4, P=.027$, respectively). There was a borderline significant decrease in PTH among those with EPA $>2 \%(-17, P=.064)$.

Changes in 25-OH vitamin D and PTH are illustrated in Figure 2 with final median values of $27.4 \mathrm{ng} / \mathrm{mL}$ and $31.0 \mathrm{pg} / \mathrm{mL}$ in compliers and $23.6 \mathrm{ng} / \mathrm{mL}$ and $36.1 \mathrm{pg} / \mathrm{mL}$ in noncompliers, respectively. There was no significant change in the biochemical markers of folate and vitamin $\mathrm{B}_{12}$ status, homocysteine, and MMA.

\section{Disease Activity and Quality of Life}

At baseline, patients had active disease and rated themselves as having a poor quality of life based on the CDAI and IBDQ (Table 2). There were no significant differences in the baseline CDAI or IBDQ between the groups. Only 6 (30\%) patients had elevated CRP $\geq 1.0$ $\mathrm{mg} / \mathrm{dL}$ at time on enrollment, and there was no difference between the groups. After 4 months, those patients with higher EPA levels had a significantly higher IBDQ (mean \pm SD, $179.1 \pm 26.6$ vs $114.6 \pm 35.9 ; P<.001)$ and lower CDAI $(116 \pm 94.5$ vs $261.8 \pm 86.5 ; P=$. $005)$ compared with those with lower levels of EPA (Table 3). There was a significant increase in IBDQ $(+41.4[23.1,47.0] ; P=.002)$ and decrease in CDAI $(-47.8[-65,-37.8]$; $P=.05$ ) in patients with higher EPA levels (Figure 3 ) and no change in those with normal EPA levels. The median CRP did not change significantly in either group (Table 3).

\section{Discussion}

Our results show that the addition of a dietary supplement enriched with fish oil, prebiotics, and antioxidants in CD results in increased fat-free and fat mass deposition, improved vitamin D status, and an improvement in quality of life and lower disease activity.

Several studies have investigated the effects of exclusive EN for the induction and maintenance of remission in $\mathrm{CD}$. These studies have shown that $\mathrm{EN}$ is inferior to corticosteroids for adults with CD. ${ }^{34}$ More promising results have been shown in children with $\mathrm{CD}$ treated with EN. ${ }^{35}$ One of the major problems with EN as the sole source of 
nutrition in adults is the high rate of noncompliance, which is partly due to the fatigue associated with a monotonous diet. There have been a small number of trials using EN as an adjuvant to a normal adult diet. On the other hand, in children, supplementation of a normal diet with nocturnal enteral feedings has resulted in prolongation of remission. ${ }^{36}$ This study was unique because the nutrition intervention was offered as a supplement to the normal adult diet. We did not place any restriction on oral intake other than the supplement and encouraged patients to eat as they normally would.

The majority of patients in this study were within the normal range for BMI. Only 1 patient was underweight and $5(15 \%)$ were overweight prior to study initiation. Studies on BMI in CD have varied, with recent reports showing an average BMI of $21-22 \mathrm{~kg} / \mathrm{m}^{2}$, consistent with our findings. Rates of overweight as determined by a BMI $>25 \mathrm{~kg} / \mathrm{m}^{2}$ have been increasing and reported as high as $32 \%$ in CD patients. ${ }^{37,38}$ The mean body fat at initiation in our patients was $33 \%$, which is considered overweight for both men and women and is higher than expected with a mean BMI of $22.6 \mathrm{~kg} / \mathrm{m}^{2}$. Several studies have shown that patients with $\mathrm{CD}$ have decreased lean mass and associated decreased muscle strength compared with healthy controls. ${ }^{38,39}$ This has been attributed to chronic inflammation, malnutrition, and long-term corticosteroid use. IBDNF consumption was associated with weight gain of both fat-free and fat tissue (almost 3 pounds each). The high protein intake along with a decreased catabolic state likely allowed patients to deposit lean tissue over 4 months. It is also possible that there was an increase in physical activity once patients' quality of life and disease activity improved, which contributed to the increased lean tissue deposition. The trend is similar to results we found in our previous study of body composition changes after infliximab, in which we saw deposition of fat and fat-free mass and a significant total weight gain. ${ }^{32}$ Studies in cancer cachexia patients with a similar nutrition supplement also showed a significant increase in lean tissue. ${ }^{40}$ Additional patients and further studies of protein metabolism would be of importance to further understand any metabolic alterations.

The addition of IBDNF led to a nonsignificant increase in energy intake $(145.9 \pm 144.69 ; P$ $=.30$ ). When looking only at those who achieved higher levels of EPA, there was an increase in total energy intake of approximately $300 \mathrm{kcal}$ or roughly one 8-oz can of the supplement (range, -162 to $+924 \mathrm{kcal}$ ). There was no significant change in the total fat and protein intake but an increase in total carbohydrates among these patients. The increase in carbohydrates was largely due to the significant increase in soluble fiber intake. Even with the addition, the total fiber intake was below the current daily recommended level, which is consistent with previous studies of CD patients and the Western diet. ${ }^{38}$ Patients with CD may avoid fiber due to physician-prescribed trials of low-residue, low-fiber diets during periods of intestinal narrowing. However, the role of viscous fiber for its prebiotic and shortchain fatty acid effects has shown significant promise, and the role of a chronic low-residue, low-fiber diet is not established. ${ }^{41}$ Although most of the changes in intake are attributed to ingredients of the supplement, a randomized controlled trial comparing IBDNF with an isocaloric, isonitrogenous supplement would provide additional information on the benefit of the fish oil, prebiotics, and antioxidants over a generic nutrition supplement. 
At baseline, patients were below the DRI for folate, vitamin D, calcium, and a-linolenic acid. As expected, there were significant increases in most micronutrients. Using the DRI for men and women younger than 50 years, all patients reached the current recommended levels for folate and calcium. Vitamin D intake improved but did not reach current guidelines of $600 \mathrm{IU}$ daily. Given the high prevalence of osteoporosis in CD patients (12\%$40 \%)^{42,43}$ and recent in vitro research that suggests that vitamin D may favorably modify inflammation and disease activity, ${ }^{44,45}$ proper supplemenatation with calcium and vitamin D in these patients is an essential part of therapy. The patients in our study had a very low intake of vitamin D at baseline (53.7 IU), a value that is well below the DRI of 600 IU daily for normal adults. After 4 months of consuming IBDNF, there was a decrease in serum PTH and a significant increase in $25-\mathrm{OH}$ vitamin $\mathrm{D}$, suggesting an improvement in the calcium axis toward less bone destruction. The increase in serum $25-\mathrm{OH}$ vitamin D corresponded with a significant increase in vitamin $\mathrm{D}$ intake to just above $400 \mathrm{IU}$. In addition, the change may also be due to increased absorption with IBDNF intake, increased production from sunlight, or decreased inflammation. Although we did not collect any data on sunlight exposure, we would like to point out that patients were enrolled and finished the research study between March and December and could have been affected by an increase in the conversion of 7-dehydrocholesterol to cholecalciferol in the skin. Despite this, it appears that the patients would still benefit from additional vitamin D supplementation because oral intake in compliant patients was below the DRI, and baseline serum concentrations were very low. Furthermore, current trends are suggesting that normal serum levels of vitamin D be $>30 \mathrm{ng} / \mathrm{mL}$, which is slightly higher than the serum levels attained in our patients.

Baseline values for plasma fatty acids in our patients are consistent with previous findings in CD patients. ${ }^{33}$ We used the final level of EPA $>2 \%$ as a biomarker of compliance based on previous trials with fish oil supplementation, low baseline values in our patients, and correlation with EPA level and recorded can intake. This subgroup excludes patients who may have been compliant but had problems with absorption. Given the normal BMI and can intake, this is less likely within our patient population. The change in the plasma phospholipid fatty acid profile with increased $\omega-3$ PUFA and decreased $\omega-6$ PUFA suggests an anti-inflammatory state. We believe that this change contributed to the improvement in disease activity and fat-free mass. Several studies have shown that $\omega$-3 fatty acids are associated with decreased proinflammatory molecules, including TNF-a, a potent inflammatory mediator in CD. ${ }^{8,46,47}$ It is known that increased inflammatory states are associated with increased fat deposition and have been implicated as mediators of obesity. Specifically, $\omega-3$ fatty acids have been implicated in upregulation of genes and proteins that regulate fatty acid oxidation in the liver, intestine, and muscle and downregulation of lipogenesis in fat tissue. ${ }^{48}$ There has also been support that these fatty acids decrease appetite and promote apoptosis of fat cells. ${ }^{49}$ Small human studies have shown that $\omega-3$ fatty acid supplementation is associated with decreased fat deposition and increased fat-free mass. ${ }^{48}$ Most of these studies have focused on obese or diabetic individuals, but the results are consistent with our findings in CD.

The primary goal of this study was not to assess disease activity; however, we recognize this is an important part of any intervention and included information on CDAI, IBDQ, and CRP. Patients were enrolled in our study if they had clinical signs of active disease; most but 
not all patients had a CDAI >150 at enrollment. We believe that the statistically significant decrease in CDAI of 47.8 points was clinically significant because this put most of the patients at a CDAI below 150 . The decrease in CDAI was accompanied by a statistically significant increase in the IBDQ. Previous studies have reported correlations between disease activity and IBD-specific quality of life with Pearson coefficients of 0.6-0.7. 31,50 The IBDQ was developed to assess common concerns in IBD patients such as bowel movements, abdominal pain, fatigue, sleep interruptions, avoidance of social activities because of limited toilet access, and anger or frustration toward the disease with scores $<170$ an indicator of poor quality of life. ${ }^{51}$ Overall, patients had an improvement in quality of life that was greatest among those who achieved higher levels of EPA with an average score above 170. Finally, even though the majority of patients in our study had active disease at baseline as measured by the CDAI and IBDQ, most had a normal CRP at baseline, with a median value of $0.3 \mathrm{mg} / \mathrm{dL}$, and only 6 patients having a value $>1 \mathrm{mg} / \mathrm{dL}$. This is most likely why there was not an improvement in CRP concentration as a result of the oral supplement. This does not necessarily mean that inflammation was not present as investigators have shown that mucosal inflammation is present in a large majority of patients with an elevated CDAI and normal CRP. ${ }^{28}$

The study patients were on stable medication dosing prior to enrollment and were not permitted to add any additional medications supporting the therapeutic effect of IBDNF. We observed a minor decrease in the dose of corticosteroids that was used in patients on this class of medications. Although our study was not powered to see whether IBDNF would lead to a reduction in the requirement for corticosteroids, our results tend to support the antiinflammatory effects of IBDNF in the compliant patients. This result is consistent with the effects of IBDNF in decreasing corticosteroid use with ulcerative colitis patients, as previously shown by our group. ${ }^{25} \mathrm{We}$ would also like to point out that most patients in this study had either tried immunomodulators and/or biologics without success or could not tolerate the side effects of these medications, and thus any improvement for these patients is of great importance.

The main limitations of this study are the post hoc analysis, small sample size, moderate dropout rate, and high rate of noncompliance. The dropout rate of $28.6 \%$ was higher than anticipated, and we therefore did not reach our initial enrollment goal. This was attributed to intolerance of the supplement in 2 patients, a decision to try a stronger medication in 3 patients, and an inability to follow-up in 3 patients. Other studies using EN to treat CD have had completion rates of $21 \% .{ }^{4}$ We anticipated better compliance than previous studies as we did not limit the patients' dietary intake or restrict the preparation or method of intake of the supplement. Side effects experienced by a few patients such as flatulence and nausea were expected at the start of the supplementation period given the type of prebiotics in IBDNF. These minor side effects have also been observed in a prior study in ulcerative colitis patients given IBDNF. ${ }^{25}$ Most patients alleviated the symptoms by gradually introducing IBDNF into their diet. At the conclusion of the study, 1 patient still complained of excessive flatulence that was alleviated with supplement cessation, and 2 patients still complained of incontinence and increased number of bowel movements that had no resolution after IBDNF cessation. 
The adverse consequences of $\mathrm{CD}$ are related to symptoms associated with abnormal gastrointestinal function and, in many cases, the result of nutrition deficiencies that occur as a result of diminished oral intake, altered metabolism, and the loss nutrients from inflamed intestinal mucosa. Most of the therapy directed toward the treatment of CD does not address the nutrition demands of the disease. We have shown that IBDNF, which is a nutritionally complete formula enriched with fish oil, prebiotics, and antioxidants, is associated with an increase in fat-free mass, an improvement in vitamin D status and quality of life, and a decrease in disease activity. These results suggest that a nutrition supplement, which can be consumed with a diet, should be taken as an adjunct to ongoing medical therapy to enhance the desired therapeutic outcome in patients with active CD. Future studies should be considered to see if this supplement would benefit patients in clinical remission, whether it would be of benefit as monotherapy in patients with minimally active disease, or if it might improve the efficacy of biologic agents through the improvement of nutrition status.

Understanding the most optimal way to determine the efficacy of these supplements through blood studies, diagnostic imaging, or tissue sampling is also of great interest.

\section{Acknowledgments}

We are indebted to the patients and their families for participating in this scientific investigation. We acknowledge the following product development and analytical support personnel who participated in the study: David Holt, John McEwen, and Christine Hastilow from Abbott Nutrition. Significant contributions to this project were made by Cindy Hamilton, MS, RD, Kristen Rhoda, MS, RD, and Rocio Lopez, MS, of the Cleveland Clinic and Steven Previs, PhD, of Case Western Reserve University.

Financial disclosure: This study was funded by Abbott Nutrition, Columbus, Ohio. All components of the study, including data analysis and manuscript preparation, were completed at the Cleveland Clinic, Cleveland, Ohio. This research was supported in part by the National Institutes of Health, National Center for Research Resources (CTSA UL1RR024989), Cleveland, Ohio.

\section{References}

1. Buchman, A.; Scolapio, J. Nutritional support in inflammatory bowel disease. In: Buchman, A., editor. Clinical Nutrition in Gastrointestinal Disease. Thorofare, NJ: SLACK; 2006. p. 225-232.

2. Geerling BJ, Badart-Smook A, Stockbrugger RW, Brummer RJ. Comprehensive nutritional status in patients with long-standing Crohn's disease currently in remission. Am J Clin Nutr. 1998; 67:919926. [PubMed: 9583850]

3. Goh J, O'Morain CA. Review article: nutrition and adult inflammatory bowel disease. Aliment Pharmacol Ther. 2003; 17:307-320. [PubMed: 12562443]

4. Griffiths AM, Ohlsson A, Sherman PM, Sutherland LR. Metaanalysis of enteral nutrition as a primary treatment of active Crohn's disease. Gastroenterology. 1995; 108:1056-1067. [PubMed: 7698572]

5. King T. Meta-analysis of enteral nutrition as a primarytreatment of active Crohn's disease. Clin Nutr. 1995; 14:388-389. [PubMed: 16843961]

6. Fernandez-Banares F, Cabre E, Gonzalez-Huix F, Gassull MA. Enteral nutrition as primary therapy in Crohn's disease. Gut. 1994; 35:S55-S59. [PubMed: 8125393]

7. Griffiths AM. Enteral nutrition in the management of Crohn's disease. JPEN J Parenter Enteral Nutr. 2005; 29:S108-S112. discussion S112-S117, S184-S188. [PubMed: 15980272]

8. Calder PC. n-3 polyunsaturated fatty acids, inflammation, and inflammatory diseases. Am J Clin Nutr. 2006; 83:1505S-1519S. [PubMed: 16841861]

9. Belluzzi A, Brignola C, Campieri M, Pera A, Boschi S, Miglioli M. Effect of an enteric-coated fishoil preparation on relapses in Crohn's disease. N Engl J Med. 1996; 334:1557-1560. [PubMed: 8628335] 
10. Lee S, Gura KM, Kim S, Arsenault DA, Bistrian BR, Puder M. Current clinical applications of omega-6 and omega-3 fatty acids. Nutr Clin Pract. 2006; 21:323-341. [PubMed: 16870801]

11. Teitelbaum JE, Allan Walker W. Review: the role of omega 3 fatty acids in intestinal inflammation. J Nutr Biochem. 2001; 12:21-32. [PubMed: 11179858]

12. Vilaseca J, Salas A, Guarner F, Rodriguez R, Martinez M, Malagelada JR. Dietary fish oil reduces progression of chronic inflammatory lesions in a rat model of granulomatous colitis. Gut. 1990; 31:539-544. [PubMed: 2161781]

13. Shoda R, Matsueda K, Yamato S, Umeda N. Therapeutic efficacy of N-3 polyunsaturated fatty acid in experimental Crohn's disease. J Gastroenterol. 1995; 30(suppl 8):98-101. [PubMed: 8563904]

14. Zhao Y, Joshi-Barve S, Barve S, Chen LH. Eicosapentaenoic acid prevents LPS-induced TNFalpha expression by preventing NF-kappaB activation. J Am Coll Nutr. 2004; 23:71-78. [PubMed: 14963056]

15. Amre DK, D’Souza S, Morgan K, et al. Imbalances in dietary consumption of fatty acids, vegetables, and fruits are associated with risk for Crohn's disease in children. Am J Gastroenterol. 2007; 102:2016-2025. [PubMed: 17617201]

16. Feagan BG, Sandborn WJ, Mittmann U, et al. Omega-3 free fatty acids for the maintenance of remission in Crohn's disease: the EPIC Randomized Controlled Trials. JAMA. 2008; 299:1690 1697. [PubMed: 18398081]

17. Kanauchi O, Suga T, Tochihara M, et al. Treatment of ulcerative colitis by feeding with germinated barley foodstuff: first report of a multicenter open control trial. J Gastroenterol. 2002; 37(suppl 14):67-72. [PubMed: 12572869]

18. Videla S, Vilaseca J, Antolin M, et al. Dietary inulin improves distal colitis induced by dextran sodium sulfate in the rat. Am J Gastroenterol. 2001; 96:1486-1493. [PubMed: 11374687]

19. Galvez J, Rodriguez-Cabezas ME, Zarzuelo A. Effects of dietary fiber on inflammatory bowel disease. Mol Nutr Food Res. 2005; 49:601-608. [PubMed: 15841496]

20. Kolios G, Valatas V, Ward SG. Nitric oxide in inflammatory bowel disease: a universal messenger in an unsolved puzzle. Immunology. 2004; 113:427-437. [PubMed: 15554920]

21. Steinhart A, Brzezinski A, Baker J. Treatment of refractory ulcerative proctosigmoiditis with butyrate enemas. Am J Gastroenterol. 1994; 89:179-183. [PubMed: 8304299]

22. Grisham MB. Oxidants and free radicals in inflammatory bowel disease. Lancet. 1994; 344:859861. [PubMed: 7916405]

23. Maor I, Rainis T, Lanir A, Lavy A. Oxidative stress, inflammation and neutrophil superoxide release in patients with Crohn's disease: distinction between active and non-active disease. Dig Dis Sci. 2008; 53:2208-2214. [PubMed: 18253831]

24. Kruidenier L, Verspaget HW. Review article: oxidative stress as a pathogenic factor in inflammatory bowel disease—radicals or ridiculous? Aliment Pharmacol Ther. 2002; 16:19972015. [PubMed: 12452933]

25. Seidner DL, Lashner BA, Brzezinski A, et al. An oral supplement enriched with fish oil, soluble fiber, and antioxidants for corticosteroid sparing in ulcerative colitis: a randomized, controlled trial. Clin Gastroenterol Hepatol. 2005; 3:358-369. [PubMed: 15822041]

26. Huang Y, Chaudhary S, Thurmond J, et al. Cloning of delta12- and delta6-desaturases from Mortierella alpina and recombinant production of gamma-linolenic acid in Saccharomyces cerevisiae. Lipids. 1999; 34:649-659. [PubMed: 10478922]

27. Best WR, Becktel JM, Singleton JW, Kern F Jr. Development of a Crohn's disease activity index. National Cooperative Crohn's Disease Study. Gastroenterology. 1976; 70:439-444. [PubMed: 1248701]

28. Denis M, Reenaers C, Fontaine F, Belaïche J, Louis E. Assessment of endoscopic activity index and biological inflammatory markers in clinically active Crohn's disease with normal C-reactive protein serum level. Inflamm Bowel Dis. 2007; 13:1100-1105. [PubMed: 17508418]

29. Henriksen M, Jahnsen J, Lygren I, et al. C-reactive protein: a predictive factor and marker of inflammation in inflammatory bowel disease. Results from a prospective population-based study. Gut. 2008; 57:1518-1523. [PubMed: 18566104] 
30. Langhorst J, Elsenbruch S, Koelzer J, Rueffer A, Michalsen A, Dobos G. Noninvasive markers in the assessment of intestinal inflammation in inflammatory bowel diseases: performance of fecal lactoferrin, calprotectin, and PMN-elastase, CRP, and clinical indices. Am J Gastroenterol. 2008; 103:162-169. [PubMed: 17916108]

31. Irvine EJ, Feagan B, Rochon J, et al. Quality of life: a valid and reliable measure of therapeutic efficacy in the treatment of inflammatory bowel disease. Canadian Crohn's Relapse Prevention Trial Study Group. Gastroenterology. 1994; 106:287-296. [PubMed: 8299896]

32. Wiese D, Lashner B, Seidner D. Measurement of nutrition status in Crohn's disease patients receiving infliximab therapy. Nutr Clin Pract. 2008; 23:551-556. [PubMed: 18849561]

33. Romanato G, Scarpa M, Angriman I, et al. Plasma lipids and inflammation in active inflammatory bowel diseases. Aliment Pharmacol Ther. 2009; 29:298-307. [PubMed: 19035968]

34. Zachos M, Tondeur M, Griffiths AM. Enteral nutritional therapy for induction of remission in Crohn's disease. Cochrane Database Syst Rev. 2007; (1):CD000542. [PubMed: 17253452]

35. Heuschkel R, Menache C, Megerian J, Baird A. Enteral nutrition and corticosteroids in the treatment of acute Crohn's disease in children. J Pediatr Gastroenterol Nutr. 2000; 31:8-15. [PubMed: 10896064]

36. Escher J, Taminiau J. Treatment of inflammatory bowel disease in childhood. Scand J Gastroenterol Suppl. 2001; (234):48-50. [PubMed: 11768561]

37. Sousa Guerreiro C, Cravo M, Costa AR, et al. A comprehensive approach to evaluate nutritional status in Crohn's patients in the era of biologic therapy: a case-control study. Am J Gastroenterol. 2007; 102:2551-2556. [PubMed: 17680845]

38. Filippi J, Al-Jaouni R, Wiroth JB, Hebuterne X, Schneider SM. Nutritional deficiencies in patients with Crohn's disease in remission. Inflamm Bowel Dis. 2006; 12:185-191. [PubMed: 16534419]

39. Valentini L, Schaper L, Buning C, et al. Malnutrition and impaired muscle strength in patients with Crohn's disease and ulcerative colitis in remission. Nutrition. 2008; 24:694-702. [PubMed: 18499398]

40. Barber M, Ross J, Voss A, Tisdale M, Fearon K. The effect of an oral nutritional supplement enriched with fish oil on weight-loss in patients with pancreatic cancer. Br J Cancer. 1999; 81:8086. [PubMed: 10487616]

41. Ewaschuk JB, Dieleman LA. Probiotics and prebiotics in chronic inflammatory bowel diseases. World J Gastroenterol. 2006; 12:5941-5950. [PubMed: 17009391]

42. Siffledeen JS, Fedorak RN, Siminoski K, et al. Bones and Crohn's: risk factors associated with low bone mineral density in patients with Crohn's disease. Inflamm Bowel Dis. 2004; 10:220-228. [PubMed: 15290915]

43. van Hogezand RA, Hamdy NA. Skeletal morbidity in inflammatory bowel disease. Scand J Gastroenterol Suppl. 2006; (243):59-64. [PubMed: 16782623]

44. Bartels LE, Jorgensen SP, Agnholt J, Kelsen J, Hvas CL, Dahlerup JF. 1,25-Dihydroxyvitamin D3 and dexamethasone increase interleukin-10 production in CD4+ T cells from patients with Crohn's disease. Int Immunopharmacol. 2007; 7:1755-1764. [PubMed: 17996686]

45. Stio M, Martinesi M, Bruni S, et al. The vitamin D analogue TX 527 blocks NF-kappaB activation in peripheral blood mononuclear cells of patients with Crohn's disease. J Steroid Biochem Mol Biol. 2007; 103:51-60. [PubMed: 17049230]

46. Zhao Y, Shao L, Teng L, et al. Effects of n-3 polyunsaturated fatty acid therapy on plasma inflammatory markers and $\mathrm{N}$-terminal probrain natriuretic peptide in elderly patients with chronic heart failure. J Int Med Res. 2009; 37:1831-1841. [PubMed: 20146881]

47. Rudkowska I, Marcotte B, Pilon G, Lavigne C, Marette A, Vohl M. Fish nutrients decrease expression levels of tumor necrosis factor-alpha in cultured human macrophages. Physiol Genomics. 2010; 40:189-194. [PubMed: 19952281]

48. Buckley J, Howe P. Anti-obesity effects of long-chain omega-3 polyunsaturated fatty acids. Obes Rev. 2009; 10:648-659. [PubMed: 19460115]

49. Pérez-Matute P, Pérez-Echarri N, Martínez J, Marti A, Moreno-Aliaga M. Eicosapentaenoic acid actions on adiposity and insulin resistance in control and high-fat-fed rats: role of apoptosis, adiponectin and tumour necrosis factor-alpha. Br J Nutr. 2007; 97:389-398. [PubMed: 17298710] 
50. Zahn A, Hinz U, Karner M, Ehehalt R, Stremmel W. Health-related quality of life correlates with clinical and endoscopic activity indexes but not with demographic features in patients with ulcerative colitis. Inflamm Bowel Dis. 2006; 12:1058-1067. [PubMed: 17075347]

51. Mitchell A, Guyatt G, Singer J, et al. Quality of life in patients with inflammatory bowel disease. J Clin Gastroenterol. 1988; 10:306-310. [PubMed: 2980766] 

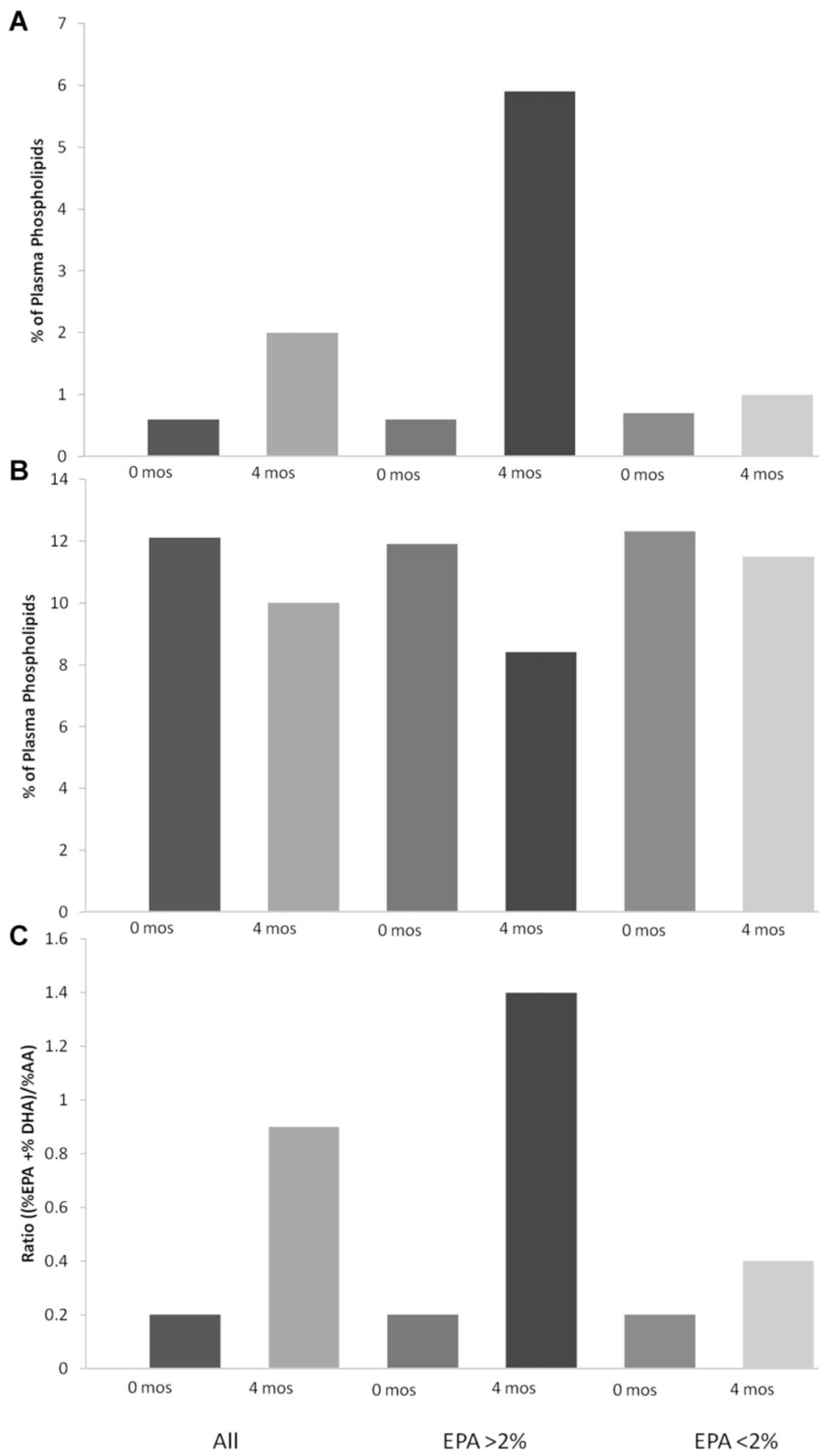

Figure 1.

Plasma phospholipid fatty acid levels. Figures depict the percentage of total plasma phospholipid fatty acid levels at baseline and at 4 months for all patients and breakdown based on final plasma EPA levels. (A) \%EPA levels, (B) \%AA levels, and (C) antiinflammatory fatty acid ratio ((EPA + DHA)/AA). AA, arachidonic acid; DHA, docosahexaenoic acid; EPA, eicosapentaenoic acid. 


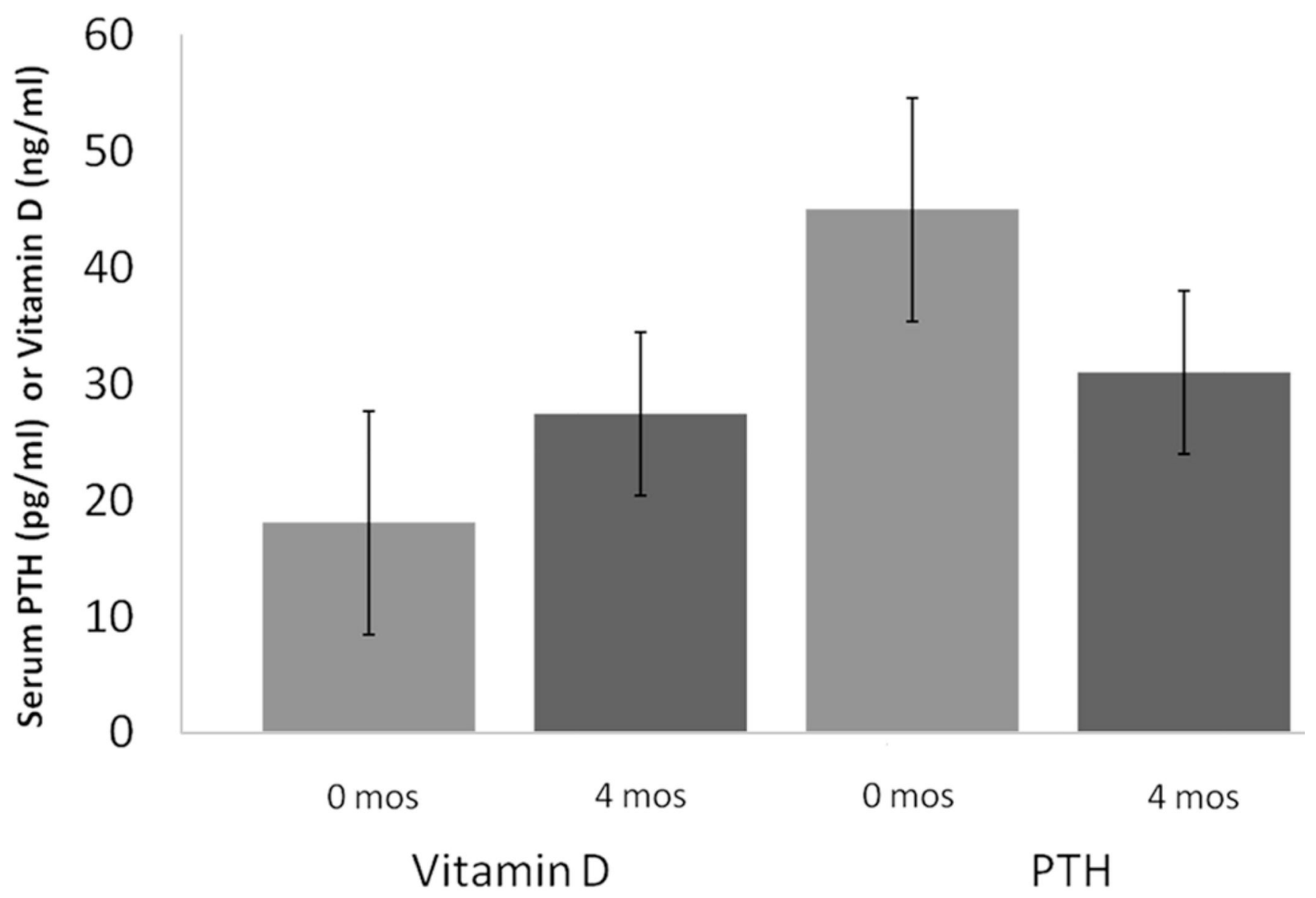

Figure 2.

Changes in vitamin D and parathyroid hormone (PTH) in patients with eicosapentaenoic acid $>2 . \%$ Figure represents the median change in vitamin D and PTH among the compliant patients before and after supplement initiation. 


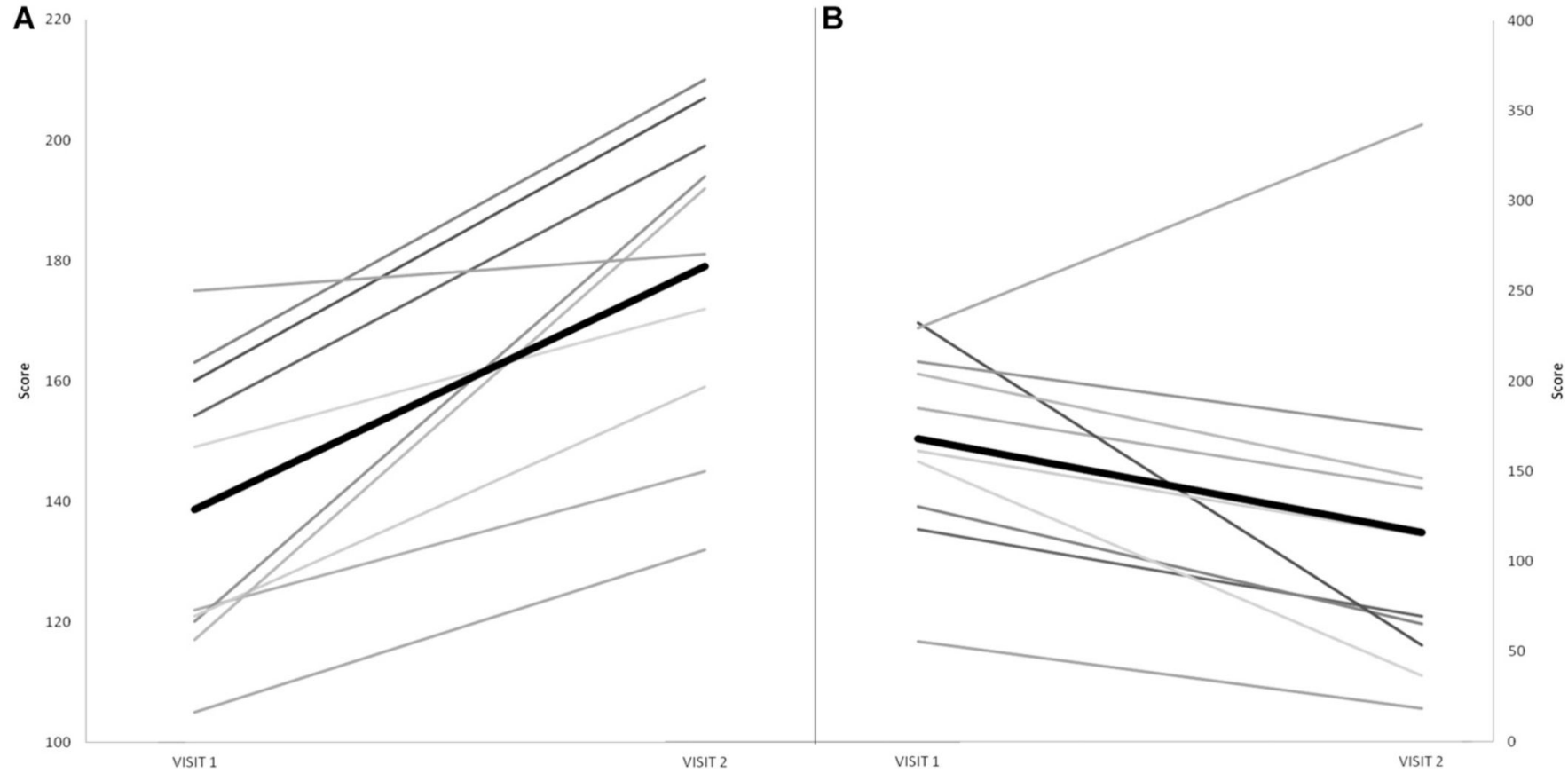

Figure 3.

Inflammatory Bowel Disease Questionnaire (IBDQ) and Crohn's Disease Activity Index (CDAI) during Inflammatory Bowel Disease Questionnaire (IBDNF) in patients with final eicosapentaenoic acid (EPA) $>2 \%$. Each thin line represents different patients' scores on the CDAI and IBDQ before and after IBDNF supplementation; the thick black line is the mean. Negative slopes for CDAI indicate an improvement in disease activity. Positive slopes in IBDQ indicate an improvement in quality of life. $P$ value corresponds to change in mean. Dotted line is approximated at 170 for the IBDQ and 150 for the CDAI. IBDQ values above 170 are considered good quality of life. Patients with CDAI values below 150 are considered to be in remission. 


\section{Table 1}

Nutrition Contents of Inflammatory Bowel Disease Nutrition Formula (IBDNF)

\begin{tabular}{|c|c|}
\hline Nutrient & Per 8 oz \\
\hline Total energy, kcal & 310 \\
\hline Protein, $\mathrm{g}$ & 16.1 \\
\hline Lipid, g & 6.5 \\
\hline Carbohydrate, g & 49.7 \\
\hline Gum arabic, $g$ & 2.2 \\
\hline Fructooligosaccharide, g & 2.9 \\
\hline Soy polysaccharide, g & 0.4 \\
\hline \multicolumn{2}{|l|}{ Vitamins } \\
\hline$\beta$-carotene, $\mu \mathrm{g}$ & 1,185 \\
\hline Vitamin A, IU & 1,320 \\
\hline Vitamin D, IU & 192 \\
\hline Vitamin E, IU & 72 \\
\hline Vitamin $\mathrm{K}, \mu \mathrm{g}$ & 32 \\
\hline Vitamin C, mg & 156 \\
\hline Folic acid, $\mu \mathrm{g}$ & 456 \\
\hline Thiamine, mg & 1.6 \\
\hline Riboflavin, mg & 1.2 \\
\hline Vitamin B6, mg & 1.2 \\
\hline Vitamin B12, $\mu \mathrm{g}$ & 4.32 \\
\hline Niacin, mg & 9.6 \\
\hline Choline, mg & 126 \\
\hline Biotin, $\mu \mathrm{g}$ & 187 \\
\hline Pantothenic acid, mg & 6 \\
\hline \multicolumn{2}{|l|}{ Minerals } \\
\hline Sodium, mg & 360 \\
\hline Potassium, mg & 480 \\
\hline Chloride, mg & 365 \\
\hline Calcium, mg & 432 \\
\hline Phosphorus, mg & 300 \\
\hline Magnesium, mg & 108 \\
\hline Iodine, $\mu \mathrm{g}$ & 42 \\
\hline Manganese, mg & 1.5 \\
\hline Copper, mg & 0.6 \\
\hline Zinc, mg & 7 \\
\hline Selenium, $\mu \mathrm{g}$ & 22 \\
\hline Chromium, $\mu \mathrm{g}$ & 30 \\
\hline Molybdenum, $\mu \mathrm{g}$ & 49.4 \\
\hline Carnitine, mg & 36 \\
\hline Taurine, mg & 56 \\
\hline
\end{tabular}




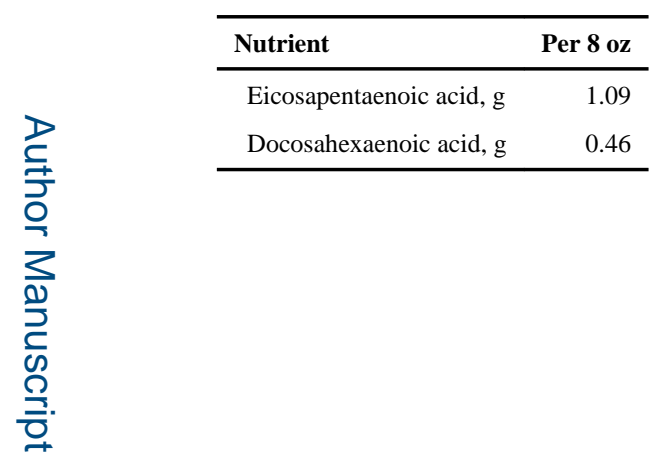

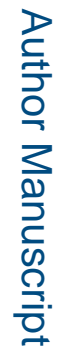

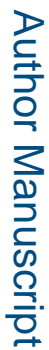

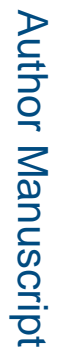

Nutr Clin Pract. Author manuscript; available in PMC 2015 June 05. 
Table 2

Baseline Characteristics of Analyzed Patients

\begin{tabular}{|c|c|c|c|c|}
\hline & $\begin{array}{c}\text { All } \\
(\mathbf{n}=\mathbf{2 0})\end{array}$ & $\begin{array}{c}\text { EPA >2\% } \\
(n=10)\end{array}$ & $\begin{array}{c}\text { EPA }<2 \% \\
(n=10)\end{array}$ & $P$ Value \\
\hline Age, y & $45.7(18)$ & $49.4(20)$ & $42(15.9)$ & .37 \\
\hline Female & $16(80)$ & $7(70)$ & $9(90)$ & .58 \\
\hline Smoker & $5(25)$ & $3(30)$ & $2(20)$ & 1 \\
\hline \multicolumn{5}{|l|}{ Disease location } \\
\hline Ileal & $7(35)$ & $3(30)$ & $4(40)$ & 1 \\
\hline Ileocolonic & $9(45)$ & $5(50)$ & $4(40)$ & 1 \\
\hline Colonic & $4(20)$ & $2(20)$ & $2(20)$ & 1 \\
\hline \multicolumn{5}{|l|}{ Medications } \\
\hline Corticosteroids & $10(50)$ & $4(20)$ & $6(30)$ & .66 \\
\hline Aminosalicylic acid & $4(20)$ & $3(15)$ & $1(5)$ & .58 \\
\hline Immunomodulators & $4(20)$ & $2(10)$ & $2(10)$ & 10 \\
\hline \multicolumn{5}{|l|}{ Body composition } \\
\hline BMI, $\mathrm{kg} / \mathrm{m}^{2}$ & $22.6(20.3,25)$ & $22.4(20.4,25.3)$ & $22.6(19.8,23.6)$ & .79 \\
\hline Fat mass, $\mathrm{kg}$ & $18.3(14.9,21.4)$ & $17(12.5,21)$ & $18.9(15.8,21.7)$ & .53 \\
\hline Fat-free mass, $\mathrm{kg}$ & $38(8.3)$ & $39.1(10.6)$ & $37(5.7)$ & .59 \\
\hline Body fat $\%$ & $33.3(10.3)$ & $31.5(10.4)$ & $35(10.5)$ & .47 \\
\hline $\mathrm{T}$ score & $-0.5(1.1)$ & $-0.5(0.9)$ & $-0.4(1.3)$ & .90 \\
\hline \multicolumn{5}{|l|}{ Nutrition markers } \\
\hline $25-\mathrm{OH}$ vitamin $\mathrm{D}, \mathrm{ng} / \mathrm{mL}$ & $18.5(8.3)$ & $18.1(9.6)$ & $18.9(7.3)$ & .84 \\
\hline PTH, pg/mL & $44.4(24.6)$ & $45(21.8)$ & $43.7(28.3)$ & .91 \\
\hline Hcy, $\mu \mathrm{mol} / \mathrm{L}$ & $10.9(9.2,13.5)$ & $9.7(7.8,13.4)$ & $11.4(10.3,13.5)$ & .24 \\
\hline MMA, nmol/L & $135.5(73,250)$ & $138(121,250)$ & $115.5(71,321)$ & .97 \\
\hline \multicolumn{5}{|l|}{ Disease activity } \\
\hline IBDQ & $126.4(35)$ & $138.6(24.2)$ & $114.2(40.8)$ & .12 \\
\hline CDAI & $204(92.1)$ & $168.2(55.9)$ & $255.1(113)$ & .10 \\
\hline $\mathrm{CRP}, \mathrm{mg} / \mathrm{dL}$ & $0.3(0.3,1.3)$ & $0.3(0.3,2)$ & $0.3(0.3,0.8)$ & .87 \\
\hline \multicolumn{5}{|l|}{ Fatty acids, $\%$} \\
\hline AA & $12.1(1.7)$ & $11.9(1.8)$ & $12.3(1.6)$ & .69 \\
\hline EPA & $0.6(0.5,0.9)$ & $0.6(0.5,1)$ & $0.7(0.5,0.8)$ & .91 \\
\hline DHA & $1.5(1.3,2)$ & $1.4(1.3,2)$ & $1.7(1.4,1.9)$ & .44 \\
\hline
\end{tabular}

Values presented as No. (\%) for gender and mean (SD) or median (25th, 75th percentiles) otherwise. $P$ values correspond to Fisher's exact test for gender, smoker, disease location, and medication and Student $t$ tests or Wilcoxon rank sum tests and compare compliers vs noncompliers. AA, arachidonic acid; BMI, body mass index; CDAI, Crohn's Disease Activity Index; CRP, C-reactive protein; DHA, docosahexaenoic acid; EPA, eicosapentaenoic acid; Hcy, homocysteine; IBDQ, Inflammatory Bowel Disease Questionnaire; MMA, methylmalonic acid; PTH, parathyroid hormone. Medications: corticosteroids include prednisone or entocort; immunomodulators include methotrexate, 6-mercaptopurine, or azathioprine. Normal reference 7.4-15.7 $\mu \mathrm{mol} / \mathrm{L}$ ranges for lab values as per the Cleveland Clinic Reference Laboratory Standards are hcy $=7.4-$ $15.7 \mu \mathrm{mol} / \mathrm{L}$ in males, $3.9-14.8 \mu \mathrm{mol} / \mathrm{L}$ in females; $25-\mathrm{OH}$ vitamin $\mathrm{D}=31-80 \mathrm{ng} / \mathrm{mL} ; \mathrm{MMA}=79-376 \mathrm{nmol} / \mathrm{L} ;$ and PTH $10-60 \mathrm{pg} / \mathrm{mL}$. 


\section{言}

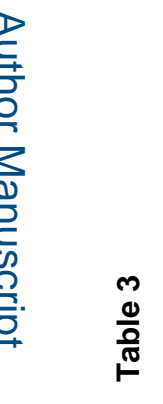

D্ 


\section{Table 4}

Nutrition Intake as Measured by 3-Day Food Diary in Patients With EPA >2\%

\begin{tabular}{|c|c|c|c|}
\hline & $0 \mathrm{mo}$ & $4 \mathrm{mo}$ & $P$ Value \\
\hline \multicolumn{4}{|l|}{ Macronutrients } \\
\hline Total energy, kcal & $2,074.77^{a}$ & $2,388.5^{a}$ & .02 \\
\hline Protein, $g$ & $77.22^{a}$ & $96.61^{a}$ & .08 \\
\hline Carbohydrates, g & $276.36^{a}$ & $329.33^{a}$ & .01 \\
\hline Fiber, $\mathrm{g}$ & 15.46 & 21.76 & .03 \\
\hline Soluble fiber, $g$ & 0.29 & 6.64 & $<.001$ \\
\hline Insoluble fiber, $\mathrm{g}$ & 1.17 & 1.15 & .64 \\
\hline Fat, g & $74.17^{a}$ & $79.45^{a}$ & .56 \\
\hline EPA+ DHA, g & 0.17 & 3.14 & $<.001$ \\
\hline $\mathrm{a}$-Linolenic acid, $\mathrm{g}$ & 0.85 & 0.93 & .28 \\
\hline Linoleic acid, $\mathrm{g}$ & 8.19 & 8.87 & .56 \\
\hline \multicolumn{4}{|l|}{ Micronutrients } \\
\hline Vitamin A, IU & $5,772.97^{a}$ & $6,628.75^{a}$ & .91 \\
\hline Vitamin $\mathrm{B}_{12}, \mu \mathrm{g}$ & $4.35^{a}$ & $12.25^{a}$ & .01 \\
\hline Vitamin C, mg & $60.76^{a}$ & $358.58^{a}$ & $<.01$ \\
\hline Vitamin D, IU & 55.27 & $431.40^{a}$ & $<.01$ \\
\hline Vitamin E, IU & 3.73 & $138.80^{a}$ & $<.01$ \\
\hline$\beta$-Carotene, $\mu \mathrm{g}$ & $1,892.55^{b}$ & $3,537.16^{b}$ & .20 \\
\hline Calcium, mg & 788.83 & $1,371.12^{a}$ & $<.01$ \\
\hline Folate, $\mu \mathrm{g}$ & 289.29 & $1,112.65^{a}$ & $<.002$ \\
\hline Iron, mg & 17.70 & 15.19 & .43 \\
\hline Selenium, $\mu \mathrm{g}$ & $97.33^{a}$ & $123.85^{a}$ & .25 \\
\hline Zinc, mg & 9.88 & $21.32^{a}$ & .01 \\
\hline
\end{tabular}

$P$ values correspond to Wilcoxon signed rank tests to assess statistical significance in baseline and follow-up diaries. DHA, docosahexaenoic acid; EPA, eicosapentaenoic acid.

${ }^{a}$ Meets current Dietary Reference Intake (DRI) requirements for average men and nonlactating, nonpregnant women younger than age 50.

${ }^{b}$ No current DRI requirements. 